\title{
Mythical Narratives of Yellow Emperor and Mythological Worship of Chinese Jade in the Classic of Mountains and Seas
}

\author{
Juan Wu \\ Department of English, School of Foreign Language, Beijing Institute of Technology, Beijing, China
}

Email address:

janewu@pku.edu.cn (Juan Wu)

To cite this article:

Juan Wu. Mythical Narratives of Yellow Emperor and Mythological Worship of Chinese Jade in the Classic of Mountains and Seas. International Journal of Literature and Arts. Vol. 5, No. 3, 2017, pp. 19-25. doi: 10.11648/j.ijla.20170503.11

Received: January 11, 2017; Accepted: March 9, 2017; Published: May 18, 2017

\begin{abstract}
Through a focus on the motif of the mythical narrative of Yellow Emperor's eating the white jade cream, this paper aims to elucidate the genetic mechanism of Chinese jade worship budded in the Shang and Zhou dynasties, unveil the underlying historical truth of the jade origination and transportation, and investigate the significance of white jade in molding the national ideology and material production.
\end{abstract}

Keywords: Mythical Narrative, Yellow Emperor, Mythological Worship, Chinese Jade, Classic of Mountains and Seas

\section{Introduction}

This paper focuses on the important mythological image of Yellow Emperor, which fully represents Chinese jade belief, seeking to reveal the non-fiction content hiding behind the fictional literary expression, to explore the hiding history and mental reality behind the fantastic literary images, to unveil the origin of jade worship, which plays a significant role in the 8000-year-old history of Eastern Asian jade culture, so that we may have an overview of the tremendous influence it has on the Chinese civilization and its psychological role in molding the national jade worship and promoting the economic value of jade business.

\section{Mythic Narrative of Jade Cream of Yellow Emperor}

Magic treasures appeared in Chinese mythological narrations relating to the ancient heroes or kings. What's different is that the material for Chinese treasures is jade, not gold. This results from the several-thousand-year "Jade Age" experienced by Chinese civilization during its formation. Gold has had a history of around 3000 to 4000 years, while jade of around 7000 to 8000 years, which is twice that of gold. ( $\mathrm{Li}$ Jinghua, 2007: 26) The Chinese mythologist Ye Shuxian adopts a pair of anthropological terms: "little tradition" to call the cultural tradition marked by metal and Chinese characters, and "great tradition" to call the cultural tradition before the appearance of characters, metals and nations. (Ye Shuxian, 2011:13) The re-exploration of the great tradition aids us to re-interpret the cultural genes and cultural encoding of the little tradition, and eventually understand the origin and characteristics of the formation of the Chinese nationality.

In The Classic of Mountains and Seas, the Yellow Emperor planted "jade flowers", which can be seen as a typical case of China's “jade bough and jade leaf": Dan River came out of the Cen Mountain, and went west into the Cheng Pool. In the river many white jades grew. So did some jade cream whose origin was boiling. The Yellow Emperor fed on this cream. Watered by jade cream for five years, the Dan plant became colorless and smelt sweet. So the Yellow Emperor took jade flowers from the mountains and planted them on the southern side of the Zhong Mountain (Guo Pu annotated: "This is the so-called jade seeds"). Beautiful jades were pretty good, solid and exquisite. With gentle luster, they shone lights and seemed soft. Since the ghosts and gods fed on jades, by wearing them, gentlemen could be protected from ominous things. (Yuan Ke, 1980: 41)

With relation to the ancestor of Chinese civilization the Yellow Emperor contains the core values of Chinese civilization that's worthy of further exploration. The 
explanation provided by Guo Pu et al. clarifies the core idea of this passage: in the San Mount. which was located in the west part of China, to the north-west of Buzhou Mount. According to Guo $\mathrm{Pu}$ et. al, there was a river named Dan River, which went west into Cheng Pool; did not produce only white jades, but also nourished jade creams that poured out like springs; and from the jade cream was born black jades; with the irrigation of the jade cream, a kind of jade trees, named Dan Tree, grew; at the $5^{\text {th }}$ year of the trees, they showed five colors and gave away five fragrances. The Yellow Emperor was the hero of this jade myth: firstly, he enjoyed the jade cream as a delicacy, the planted jade trees: he used the jade follower produced by the jade of the San Mount. as jade seeds, and planted them on the south side of Zhong Mount. Thus produced the best jade materials which was called "Jin Yu Jade" (beautiful jade). According to Zuo Zhuan: Xuan 15., "a saying goes that "your status is determined by how tolerant your heart is, like rivers and ponds that accept wastes, like mountain lakes that hide sickness and like the beautiful jade that conceal flaws"'. According to the statement by Kong Yingda, "Jin Yu, the beauty of jades". According to Beautiful Jades that Hide Conceal Flaws written by Ouyang Zhan of Tang Dynasty, "the beauty of jade is called Jin Yu". In Classic of Mountains and Seas: Classic of the Mountains,: "to worship the god of mountains, one hundred Yu was needed". According to Guo Pu's illustration, "Yu is the name of beautiful jades".

\section{Theoretical Structure and Psychoanalysis of Jade Mythology}

Such jades were characterized by harshness, density and heaviness, giving out gentle luster and appearing colorful like the original Dan Tree. Such characteristics and appearance of Jin Yu jades fully display the concept of jade virtues illustrated by Confucius, the connoted value of "overcoming the hard with the gentle" and the traditional custom of "a gentleman must wear jades" etc. The "Jin Yu jade" planted by the Yellow Emperor has the same magic as the "golden bough" in the western myths. The Classic of Mountains and Seas briefly refers to its two functions: first, being the delicacy enjoyed by the gods and ghosts to increase their supernatural powers; second, being worn by gentlemen to protect them from the evil and unlucky things. These two functions of Chinese jades make them the bridge connecting man and god. It associates the origin of jade-worship culture with Chinese national ancestor, the Yellow Emperor, which can be viewed as the "Genesis" of Chinese civilization in the national memory.

Therefore, jades explicitly become the secular bonds between man and god and the holy media to realize "the integrity of man and god". Certainly, jades also turn to be the literary theme of many poets and writers throughout the ages. Many works evoke similar holy articles to construct their space of imagination and fantasy. Let us first see the recreation of "jade cream". In Guo Pu's illustration, he quoted from The Map of Rivers: "on the Shaoshi Mountain, there is white jade cream. Once "fu" the cream, man will become an immortal". The Chinese "fu" can mean two actions: "to eat (food)" and "to wear (clothes, jewelries etc.)". Here, it's more proper to be interpreted as "to eat". No matter man ate or wore the jade cream, man got the magic of becoming an immortal being. In Song to the South Capital, Zhang Heng of the Han Dynasty said: "ganoderma lucidum grew in the houses, and jade cream filled all corners of the houses". Here, jade cream is put together with another magic medicine in Chinese medical myths -ganoderma lucidum. In the first volume of Encyclopedia of Nature, Zhang Hua of the Jin Dynasty said: "among the famous mountains and rivers, inside the holes and caves, natural Qi interacts and consequently gives birth to stone juice and jade cream. Eating them, man will not die." In his fourth poem Reading The Classic of Mountains and Sea, Tao Yuanming said that "Where does the Dan Tree grow? On the south of Mi Mountain, yellow flowers and red seeds. Eating them, life expands. White jade produces juices, beautiful jades shine magic lights. Aren't they gentlemen's treasure? So much treasured by our Yellow Emperor". (Dai Qinli, 1979: 135)

Tao did not only love singing the story of Yellow Emperor's eating jade cream, but also imagined the jade cream as the juices from white jades, which inspires the later generation fantasy about jade juices. According to Bibliographies of Immortals: "Chisong Tzu, the rain god of the Shennong era. He ate jade juices and could not be burnt when he was in fire. He taught this secret to Shennong". In Records of Ten States: "Ying State has jade cream like wine, name jade wine. Drinking several litres, man won't die". The previous writers, relating to Yellow Emperor's jades, were leading the observation of natural things to the core concept of immortality. They were more of the inheritance from the prehistoric jade myths, than the creation of ancient men of letters. Seen from the description of "beautiful jades shine magic lights", the difference between the west and east mythologies - gold worship and jade worship - results from the difference of the lightening minerals. The luster and color of gold obsessed the Greek and Roman writers, in the same way beautiful jades, jade cream and jade flowers obsessed those Chinese writers. (Bernstein, 2008: 1-6)

The Classic of Mountains and Seas described the geographic scope where the Yellow Emperor planted the jade flowers: he got the jade seeds from San Mount. and planted them in the south side of Zhong Mount. "It was $460 \mathrm{li}(230 \mathrm{~km})$ from San Mount. to Zhong Mount." How did Yellow Emperor cover such a distance? We can't know. We also have no idea about how the local white jade cream of San Mount. gave birth to black jades, which seemed to be mysterious and magical. The white and black colors and their interaction make us think of the Taiji Tu. Jade myths break the limitations of things which cannot happen in the real world and build an integrated magical world. Penetrating the complicated and confusing appearances, we can grasp the basic concepts of jade myths: jade represents god, represents magical changes, and represents immortal lives. These three connotations are enough to construct the core values of a culture. 
In the Period of Warring states when The Classic of Mountains and Seas was written, gold had finished its millennium journey from the Western Regions to the Central Plains' civilization. (Ye Shuxian, 2009: 56) The most common narrative mode of this book is the resource reports of the mountain and rivers which emphasizes both the gold and jade. For example, in Classic of the Mountains: West, Zou Mount. is recorded that "there are no grass or trees on it. Qi River comes out of it and goes west into the sea. In the river, there are many colorful stones, gold and cinnabars". (Yuan Ke, 1980: 32) Shuli Mount. is described that: "on the mountain, there is plenty of golds. At its foot, there is variety of silvers. Most of its trees are large and stark and most birds are parrots. Chu River comes out of it and goes west into Wei River. In the river, there are many white jade balls." (Yuan Ke, 1980: 34) Longshou Mount. is recorded that: "on the south side of the mountain is much gold and the north side iron. Tai River comes out of it and goes southeast to Jing River. In the river, there are many beautiful jades". (Yuan Ke, 1980: 35) Zhongshou Mount.is depicted that: "many jades dispersedly float on it. At its foot are many wingceltis and tangerines and gold. Most of its beasts have sharp horns." (Yuan Ke, 1980: 37) In such report mode which emphasizes both metal and jade or stone resources, all gold, silver, bronze and iron are included, which have great economic values to human life. But none of them can compete with jade in the way it is closely connected to the ancestor of Chinese civilization and turns into magic articles.

\section{Yellow Emperor and Myth of Kunlun Mountain}

There are numerous mineral resources of different places recorded in the Classic of Mountains and Seas, which provide us with sufficient documentary evidence to interpret the historical evolution of jade mythical ideology. In the Classic of Mountains and Seas, there are more than 140 mountains that produced jades, 16 of which produced white jades. And among these 16 white-jade-producing mountains, the $7^{\text {th }}$ one, i.e. the Mi Shan Mountain was the one described in most details. Mi Shan was in the same volume as Kunlun: the volume of Classic of the Mountains: West. Of the Classic of Mountains and Seas, this passage is the best part of describing and worshiping jades. Firstly, what it described is a special kind of white jade. Secondly, the white jade can magically transform and produce and be produced. It turns into jade cream, and then white jade cream produces black jade, which fully demonstrates the secret of Yin-Yang change. Thirdly, the jade cream is nutritious, being able to be the food of the Yellow Emperor who was the Chinese ancestral god and it is the food of ghosts and gods. This means, the jade is eatable.

The jade cream brings with the physical transformation or even magic immortality, which satisfy the desire and initiate the imagination of the rulers. The jade flowers of Mi Shan were taken by the Yellow Emperor and planted on the southern side of the Zhong Mountain. What was produced was named as Jin $\mathrm{Yu}$ (beautiful jade), and its fine qualities are described as "solid and exquisite", which are in accordance with two nowadays indicators in testing the jades: high hardness and great density. Beautiful jades were pretty good, solid and exquisite, and also shined lights, and Guo $\mathrm{Pu}$ annotated as "the jade is smooth and thick". It is moist.and shining, this is how the ancient people described the physical characteristics of Hetian jade at Kunlun Mountain -shining as oil, which is the "oil quality" of jade. A contrarian indicator is "water quality", i.e. being dry and rough, which will greatly influence the feeling quality of jades. Without experience Chinese intuitive feeling of the jades, people will have difficulty understanding this description about these qualities of the supreme jade materials. Such description of jade resource seems to be ordinary; however, from the viewpoint of cultural anthropology, it requires the internal perspective of jade cultural holder, i.e. "from the perspective of an aborigine", to grasp the essence in the context. Such description will become a farfetched and unreasonable anecdote when detached from the particular context of Chinese jade culture.

In ancient literary documents, only the white jades enjoysuch magical description. It can be speculated that, in the ancient people's imagination, the white jades have greater power in communicating with the gods and spirituals than jades of other colors. As for why white jades are connected with such mysterious and magical imaginations, we can refer to the expressions in classic literature (such as the shining objects in the sky - the sun and the moon, are both compared to white jades) to decode that logic of unification of man and god.

Since Yellow Emperor, worshiped as the national ancestor by Chinese people, thus the myth of his eating the white jade cream also has a deep influence on Chinese civilization, especially on the naming of food. When it comes to white food (from the white drinking liquid to the white jelly tofu), the Chinese often have beautiful imaginations, such as jade juices, brocade clothes and jade food. The phase - jade food, became common in the literature of many scholars and intellectuals. In Shang Shu: Great Plan of Jizi, the privileges of the monarch are described as: "only the monarch can enjoy happiness, only the monarch can act as a tyrant, and only the monarch can eat jade food. There is no official who enjoys happiness, acts as a tyrant, or eats jade food." (Jiang Shanguo, 1988: 112) Kong Chuan recorded that: "only the monarch has the privilege of acting as a tyrant, enjoying happiness, and eating delicious food." The later generation use the idiom of "acting as a tyrant and enjoying happiness" to mean holding power over someone' life and property. In his commentary, Sun Xingyan said: "what is means is that, the monarch should perfect his nature, so that he can be moderate and control his temper so that he can perform his privilege in enjoying happiness and acting as a tyrant." In Shi Gu, the author said: "it talks about the monarch. And the jade food is delicious food." (Sun Xingyan, 1986: 309) In Book of Wei: Biography of Chang Jing, the author said: "behaving like this, your house will be safe even you have gorgeous pavilions and gold doors; the life of wonderful clothes and jade food can keep you fit."(Wei 
Shouzhuan, 1974:101) In poem Feelings of Reading in a Rainy Autumn Night, Lu You said: "the officials in charge of the monarch's dining recommend jade food, while the ordinary people only have delicious cress." In Cautious about Marriage: Love Visits written, a drama by Li Yu, a character said: "you hold yourself much too aloof. You abandoned your house of red doors and jade food, and came to such a shabby valley to ask for bamboo mat and gourd ladle." (Ou Xiaomu, 1981: 132) This is a metaphor unique to Chinese, from the jade cream of the Yellow Emperor, to the jade food of all monarchs and the wonderful clothes and jade food or the red doors and jade food of high officials and noble lords. When examining its origin and inheritance, the myth of the Yellow Emperor's eating jade cream in Classic of Mountains and Seas is obviously the prototype of these narrations and imaginations.

Emperor $\mathrm{Wu}$ of Han who was obsessed about achieving immortality through eating jade food valued very much the jades collected from the faraway Western Regions. In Records of the Grand Historian: Treatise on the Dayuan, there is description about the Emperor examined the ancient books by himself to name the mountains in the west which produced jades. It is very likely that Emperor Wu of Han took Classic of Mountains and Seas as reference to name "Kunlun" when he was inspecting the samples of beautiful jade brought to the court by messengers of Xinjiang.

\section{Complex of Jade Worship and Origin of Chinese Civilization}

In Chu Ci: Nine Songs: The Lady of the Xiang, Qu Yuan said: "take white jades to press the seats, and spread the Folium Pyrrosiae to make the room full of fragrance."We can know that, since the Eastern Zhou Dynasty, the white jades have stood out of jades of various color and became the subject praised by poets. The charm of white jade resulted from a conceptual revolution of jade beliefs which was the first time in history, i.e. the worship of jades of any color to the worship of jade of pure white. I call this big revolution of mythological concepts as the "Protestant Revolution" of the jade religion. The background of this revolution was, Hetian jades of Kunlun Mountain in Xinjiang was transported into the Central Plains on a large scale, which started the new tradition of transporting jades from the west to the east which lasted for 3 to 4 thousand years. Since perfect white jades can only be found in Hetian jades of Xinjiang, the white jade worship didn't appear in thousands of years' prehistoric jade culture. It was obvious, at that time there was yet no cultural revolution of "transporting jades from the west to the east", so no white jade materials was available in producing jade sacrificial vessels or in the system of jade rituals. Once the rulers of the central plains found and started to use the white jade, the subject of worship in their ideology witnessed significant changes. Viewed from this, in Classic of Mountains and Seas, one of the 16 listed mountains that produced white jades was named as "White Jade Mountain". This is no coincidence. We can speculate this book is the secret treasure map of those devout believers after the Protestant Revolution (the white jade worship) of Chinese jade religion came into being.

According to modern mining, white-jade-producing mountains in China are very rare, impossible to amount to 16 in number. However, more than 2000 years ago, Classic of Mountains and Seas stated this with great certainty and specific specialties. When the author introduced each of the 140 mountains, he first recorded whether it produces jades, then talked about whether it has white jades. It could not be a simple coincidence, since such mode pf sequence appeared repetitively more than 16 times. From this, we could see that the jade and the white jade are differentiated holy articles. In Tale of King Mu, Son of Heaven which came into being in the Warring States period, jades of different colors were also emphasized. For example, according to narration in Volume 2: King $\mathrm{Mu}$ visited the Yellow Emperor's Palace at Kunlun Mountain, and worshiped Kunlun with sacrifices; later, he went further north and stayed at a place named as Zhu Ze (jade pond), by whose bank King Mu fished and said: "Zhu Ze's water spreads an area of $30 \mathrm{Li}$ " (Guo Pu, 1992:217). The following narration immediately after this one is: "Then $\square$ white jade/s was/were presented."

Here, the subject who presented the white jade was not mentioned. With only the predicate and the object, we are not clear that who presented this white jade and how many jades were presented. According to the annotations by Guo $\mathrm{Pu}$ and Hong Yixuan of the Qing Dynasty, Shi Wu Ji Yuan thought that "people living in Zhu Ze region presented white jade(s) material to King Mu". (Guo Pu, 1992: 217) The subject is added, thus we know that it was the local people of Zhu Ze who presented white jade material to King Mu. After that, more things with larger scale were presented to him, "So, 300 horses and 3000 cattle and sheep were presented to King Mu." (Guo Pu, 1992:212). The inscriptions on bronze objects that recorded how the Emperor of the Western Zhou awarded his officials, unfold the fact that the jade and the horse were the two most important treasures of that time and in the charge of the supreme ruler, which played an essential role in the construction of the power network and stratified hierarchy of the Western Zhou Dynasty. Among all jades transported from the west to the east, the white jades, because of its rareness, are more precious than others.

In Classic of Mountains and Seas, 16 of the more than 140 jade-producing mountains produce white jades, with the other more than 120 mountains only produce jades of other colors, and white jades only account for $11 \%$ of the total jades. The 16 white-jade-producing mountains are: Yuanyi Mountain, Jiwei Mountain, Kuishan Mountain, Dashi Mountain, Lutai Mountain, Xiaoci Mountain, Mishan Mountain, Leyou Moutain, Youshou Mountain, Jinggu Mountain, Zhongqu Mountain, Niaoshutongxue Mountain, Baisha Mountain, Yizhu Mountain, Geshan Mountain and Xiongshan Mountain. Besides, there is another mountain whose name is "White Jade Mountain". As for the geographic positions of these mountains recorded in the Classic of Mountains and Seas: 3 of them are included in Classic of the Mountains: South, 9 in 
Classic of the Mountains: West, 1 in Classic of the Mountains: North, 0 in Classic of the Mountains: East and 3 in Classic of the Mountains: Central. So, geographically, 56\% of white-jade-producing mountains gather in the region recorded by Classic of the Mountains: West, more than the 44\% which totals those in the Classic of the Mountains: South, Classic of the Mountains: North, Classic of the Mountains: East and Classic of the Mountains: Central. The Classic of Mountains and Seas was regarded as the treasure house of ancient ideas, from which we can see that, for generations of ancient Chinese, the geographical and mining knowledge made them firmly believe that the mountains in China's west plateau are the main place producing white jades. With the popularity of Thousand Character Classic which tell that "jade comes from Kunlun", people gradually think that the Kunlun Mountain is the only place that produces white jades and other places are forgotten.

Till the $20^{\text {th }}$ century, the Hetian jades of Xinjiang became deteriorated. So people started to look for and mine substitutes for Hetian jades. Then, the other two white-jade-producing places are discovered: Baikal in Russia and Golmud in Qinghai, China. In the jade industry, white jades from Baikal are called "Russian materials", and those from Golmud "Qinghai materials" (or Kunlun jades). Compared with Heitian white jades of Xinjiang, the Russian materials are whiter in color, yet with little worse in oily texture; while, the Qinghai material are grayish white in color, have hidden water lines, better translucency and much worse in oily texture.

In 2014, in a cultural delegation of the Jade Road to Gansu Province, a 23-kilometer-long mountain located in Guazhou, Gansu Province is discovered, which produces shining white jades at the northern part of Datou Mountain. The sampling report tells that the Mohs' hardness of jades here is 6, with all major indexes equal or close to the Hetian jades of Xinjiang. The only difference is that there is visible difference in their white colors. The Hetian white jades are usually slightly greenish; however, the white jades of the Datou Mountain are slightly yellowish. This illustrates that in the western plateau of China, there are multiple places that produce white jades. It remains a mystery how much unknown jade materials are mined from here. The 16 white-jade-producing mountains recorded in the Classic of Mountains and Seas can't be fabricated in the study, but based on sordid investigation.

Besides the white jades, in Classic of Mountains and Seas, another 11 mountains are recorded as producing blue and green jades, and another 8 mountains as producing water jades, i.e. crystals; and in the chapter of Classic of Mountains: Central, 5 mountains are recorded as producing "White Min (beautiful stones)". In Xunzi: Lawful Behaviors, the author said: "so, although Min is colorful, it's no match for the white and shining jade." Here, the grades of Min and white jade are differentiated. In Book of Han: Sima Xiangru (Part 1), the author said: "the stones there include Chi Yu (red jades), Mei Gui (a kind of beautiful rosy jades), Lin (a kind of beautiful jades) and Kun $\mathrm{Wu}$ (name of a kind of stones which are inferior to jades)". In Yan Shigu's annotations, he cited Zhang Ji as: "Lin is a kind of jade. And Min is stone that is inferior to jades." Though the ancient people prefer white jades to Min, they also paid attention to white Min as substitution of white jades under the condition that white jade materials were rare. If not so, Min won't be listed by Classic of the Mountains and Seas as one of the special resources. This also proves the white jade worship in the mind of the authors of Classic of Mountains and Seas.

\section{Mythological Ideology and Cultural Function of Jade Mythology}

The Yellow Emperor is regarded as the ancestor of humans and in terms of the geological location, he lived in the holy Kunlun Mountain, which represents the source of Chinese mother river and the source of beautiful jades, thus to some extent, the secrets of Kunlun myths are exactly that of Chinese civilization. According to annotation of Gao You: Xuanyuan is the alternative name of the Yellow emperor. The Yellow Emperor's Palace starts from the Kunlun Mountain, as recorded in Tale of King Mu, Son of Heaven: Son of Heaven ascended up the Kunlun Mountain to view the Yellow Emperor's Palace. He asked for jades, and saw what they were like. In Classic of Mountains and Seas, the Yellow Emperor took jade flowers of Mishan Mountain and planted them on the southern side of the Zhongshan Mountain. In Tai Bai Yin Jing, the Yellow Emperor took jades as weapons. Similar cases can be found in Yue Ju Shu. In Biography of Xuanyuan, the Yellow Emperor: at the outset of the new regime, the Yellow Emperor divided the state into divisions, then ordered the governors of hundreds of counties to entitle those who taught virtues to the people, first arrange Gui jade on the cattail mats to differentiate the central Chinese and the western tribes. Thus, the Yellow Emperor might be the first Chinese who used jades. (Zhang Hongzhao, 2010: 96)

When Zhang Hongzhao identified the Yellow Emperor might be the first jade holder, there was no discipline of archeology at that time. Nowadays, according to archeological findings, the earliest jade could be traced back in Xinglongwa Culture which dated back to 8000 years ago and 3000 years earlier than the era of the Yellow Emperor. Based on the jade worship of the dynasties of the Central Plains, the origin of the myth of the Yellow Emperor could be deduced to the Shang and Zhou dynasties which are 3000 years ago. The revolution of the jade religion brought by the white jades make the later sublime rulers focus not only on the white jades, but also the places producing white jades. King $\mathrm{Mu}$, the $5^{\text {th }}$ emperor of the Western Zhou Dynasty, spared every effort to visit the Queen Mother of the West at Kunlun can be taken as the symbolic incident to demonstrate to the popularity of white jade worship. After the Western Zhou Dynasty, the jade worship evolved into the direction of immortality, which accounts the reason why the narration of Yellow Emperor eating the boiling jade cream of Mishan Mountain appeared in Classic of Mountains and Seas. Guo Pu cited He Tu Yu Ban: "on the Shaoshishan Mountain, there is white jade cream. And once drank the cream, people will become immortal." (Yuan Ke, 
1980: 41) The white jade cream of Mishan Mountain, shares the same mythological function of immortality as that of the jade flower of Western Kunlun Mountain. As for this, Book of Han: Biography of Sima Xiangru cited from Da Ren Fu: "breathe the vapor of nights and eat the rosy glow of dawn, chew ganoderma flowers and eat some jade flowers." In Yan Shigu's annotations, he cited Zhang Ji as: "The jade tree grows at the bank of western river of Kunlun Mountain, with the perimeter of 300 Wei (the perimeter of two arms enclosed) and the height of ten thousand Ren (1 Ren means around 1.76 meters). The stamen or pistil of its flowers, being eaten, can make people immortal."

The connection of jade worship and ideal of immortality could be generated from the permanent shining objects, such as the stars, sun, moon, etc. In one of the poems of Li Bai, a famous poet in the Tang Dynasty, the moon is described metaphorically as "white jade plate", which vividly demonstrates the immorality of white jade in the Chinese mythological thoughts. From the Yellow Emperor's eating jade cream to the Queen Mother of the West's presenting white jade ring, though the protagonists are different in gender and identity, yet what is the same is more important, i.e. the pursuit of spiritual values in jade worship and the idea of associating white jade with sublimity and immortality. The Chinese phrase "Bai Bi Wu Xia (flawless white jade, used to describe impeccable moral integrity of a man), could be taken as the secular extension of the holy ideal of white jade and sparked by the constant interaction myths of man and jade in the special cultural context of Chinese civilization. On the premise of this, the function of white jade at the Hongmen dinner (a dinner at Hongmen Where treachery - murder of the invited guest -- was planned) as described in Records of the Grand Historian and the First Emperor of Qin chose a white jade - the jade of the $\mathrm{He}$ family to make the Imperial Jade Seal that passed from one dynasty to the next could be fully understood.

\section{Conclusion}

So far, there is no consensus on how Classic of Mountains and Seas came into being. Some say it was made in the Xia Dynasty, some in the Shang Dynasty, in the Western Zhou Dynasty, Eastern Zhou dynasty, the Han Dynasty or others. According to the latest unearthed antiques, we can roughly confirm that the white jade worship could be traced back to the Shang and Zhou Dynasty, and the large-scale application of white jade is a phenomenon after the middle period of Western Zhou Dynasty. Among the holy jades that symbolize the holy power as reflected in literary documents like Shang Shu: Testamentary Charge, we can see list of local jade materials including Yi Jade and Yue Jade, which are also great in number. So far, the white jade worship was still at the early stage, with its unique creeds and concepts not formed yet. If not, there wouldn't be so many local jades of multi colors that were also regarded as precious treasure of the royal family of Zhou Dynasty. The saying of "Kun Mountain Jade" began to become the national common sense since the
Warring States Period. So the old names- "Qiu Lin", "Lin Lang" and others are then replaced. That was why their meanings were not even known by the learned scholar Guo $\mathrm{Pu}$ of the Jin Dynasty. Currently, Classic of Mountains and Seas is the only ancient book that recorded the white jade resource and its production areas in many details and in a comprehensive manner. For this matter, its valuable significance can only be known by white jade worshippers. In the early ideology of Chinese civilization, white jade is important with its double functions of being both material resource and spiritual worshipping object. With the narration of supernatural and mythological elements, the reliable of relevant information in Classic of Mountains and Seas is proved sordidly by the inheritance vein of jade culture discovered by the findings of archeology. To some degree, the Classic of Mountains and Seas can be seen as the first book of the early white jade worshippers in Chinese civilization. The date of book might belong to the Eastern Zhou Dynasty, since it should have the material premise of frequent jade transportation from the west to east, it can't appear in the Xia Dynasty and Shang Dynasty when the jade transportation from the west to east had just begun.

The myth of the Yellow Emperor's eating the white jade cream, as recorded in Classic of Mountains and Seas, is the recreation of mythological imaginations nourished by the historical reality in the early state of the Central Plains. The prototype and motif of such imaginations came from the worship of Hetian Jade, especially the white nephrite, by the state rulers in the Central Plains. All such mythological motifs, no matter the white jade cream that produced black jades, the Yellow Emperor's planting the jade flowers, the Kunlun Jade Mountains (the Mountain of Jades) where the Yellow Emperor lives or the Jade Lake, typically illustrate Chinese indigenous worship for the white jades. Max Weber once pointed out that, "The supreme gold of social sciences is not to pursue the construction of new ideas or new concepts, but to make efforts in understanding the cultural meaning of concrete historical links". (Weber, 1999: 60) The genetic study of white jade worship, which is particular to Chinese civilization, deepens the understanding of the connotative significance of jade mythological narrative, the philosophical ideals of jade ideology and historical information of the origin of Chinese Civilization.

\section{Acknowledgements}

This paper is supported by the research project of "Study on Literature and Lepidoptera of Vladimir Nabokov" [Project Number: 3240012211705], Fundamental Research of Technological Innovation Program, Beijing Institute of Technology.

\section{References}

[1] Allan, Sarah. The Heir and the Sage: Dynastic Legend in Early China [M]. San Francisco, CA: Chinese Materials Center, 1981. 
[2] Allan, Sarah. The Shape of the Turtle: Myth, Art, and Cosmos in Early China [M]. Albany, NY: State University of New York Press, 1991.

[3] Cao, Xueqin. A. Dream of Red Mansions[M]. Vol. 8 of the annotated version. Beijing: Beijing Normal University Press, 1987.

[4] Ge, Hong. Yang Zhaoming's Index to the Outer Chapters of Baopuzi [M]. Shanghai: Zhonghua Book Company, 1991.

[5] Guo, Pu. Classic of Mountains and Seas Collated and Annotated by Guo Pu [M]. Changsha: Yuelu Publishing House, 1992.

[6] Jiang, Shanguo. Shang Shu [M]. Shanghai: Shanghai Classics Publishing House, 1988.

[7] Na, Zhiliang. Pictorial Illustrations to Ancient Chinese Jades [M]. Taipei: SMC Publishing Inc., 1990.

[8] Ou, Xiaolu. Collections of Lu You[M]. Beijing: Ren Ming Publishing House, 1981.

[9] Pang, Pu. One Divided into Three: Research On and Interpretation of Traditional Chinese Ideas[M]. Shenzhen: Haitian Publishing House, 1995.

[10] Ruan, Yuan. Annotations to the 13 Classics [M]. Shanghai: Zhonghua Book Company, 1980.

[11] Sun, Xingyan. Annotations to and Comments on Old and New Articles of Shang Shu [M]. Shanghai: Zhonghua Book Company, 1986. P.309.

[12] Weber, Max. The Methodology of the Social Sciences [M]. Trans. Han, Shuifa et al. Beijing: Central Compilation \&
Translation Press, 1999.

[13] Wei, Shouzhuan. Book of Wei: Biography of Chang Jing [M]. Beijing: Zhong Hua Publishing House, 1974.

[14] Ye, Shuxian. Cultural Semiotics -_New Horizon of Great and Small Tradition [M]. Shanxi: Shanxi Normal University Press, 2011.

[15] Yuan, Ke. Collation and Annotation to Classic of Mountains and Seas [M]. Shanghai: Shanghai Guji Publishing House, 1980.

[16] Zhang, Hongzhao. The Elegance of Stones [M].Tianjin: Baihua Culture and Art Publishing House, 2010.

\section{Biography}

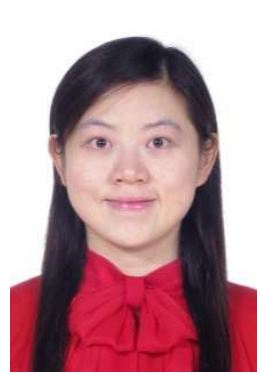

Juan Wu mainly engages in the study of English Literature and Literary Theory, Cultural Studies, Comparative Mythology, is a lecturer at School of Foreign Language, Beijing Institute of Technology and an academic visitor of Faculty of English Language and Literature, University of Oxford (2015-2016). She has authored Vladimir Nabokov: "A Rigid Moralist" and numerous articles on academic journals. Recently she focuses on Chinese Jade Mythology, and Literature and Lepidoptera of Vladimir Nabokov. 